Université de Paris, Epidemiology and Statistics Research Center/CRESS, INSERM U1153 EPOPé, INRA, Paris, France

2 Elizabeth Garrett Anderson Institute for Women's Health London, University College London, London, UK

3 Department of Neonatal Medicine, Maternité Port-Royal, Association Publique des Hôpitaux de Paris (APHP), Paris, France

4 Department of Psychology, University of Warwick, Coventry, UK

5 Department of Neuroscience, Psychology and Behaviour, University of Leicester, Leicester, UK

6 European Foundation for Care of the Newborn Infant, Munich, Germany

National Institute for Health Research, University College London Hospital Biomedical Research Centre, London, UK

Correspondence to AS Morgan andrei.morgan@inserm.fr https://orcid.org/0000-0003-4143-1977 Cite this as: BMJ2022;376:e055924 http://dx.doi.org/10.1136/bmj-2021-055924 Published: 10 January 2022

CLINICAL UPDATES

\title{
Management and outcomes of extreme preterm birth
}

\author{
Andrei S Morgan, ${ }^{1,2,3}$ Marina Mendonça, ${ }^{4,5}$ Nicole Thiele, ${ }^{6}$ Anna L David ${ }^{2,7}$
}

\section{What you need to know}

- Overall survival of babies born extremely preterm has improved in recent years, but evidence for improvements in longer term neurodevelopmental outcomes is limited

- Recent changes in obstetric care include how, when, and to whom to administer steroids, surfactant, and new treatments such as antenatal magnesium sulphate or delayed cord clamping and placental transfusion

- Active participation of parents in treatment may positively influence bonding as well as longer term outcomes for child and family

- Variability in provision of care for extreme preterm birth has an impact on morbidity and mortality outcomes

- Extreme preterm birth has a social impact on mothers, fathers, children born preterm, and their families; the value of investing early in life to prevent later complications is now widely recognised

Extreme preterm birth, defined as birth before 28 weeks' gestational age (box 1 ), ${ }^{1}$ affects about two to five in every 1000 pregnancies, and varies slightly by country and by definitions used. Severe maternal morbidity, including sepsis and peripartum haemorrhage, affects around a quarter of mothers delivering at these gestations. ${ }^{2}$ For the babies, survival and morbidity rates vary, particularly by gestational age at delivery but also according to other risk factors (birth weight and sex, for example) and by country. ${ }^{34}$ In this update, we focus on high income countries and provide a broad overview of extreme preterm birth epidemiology, recent changes, and best practices in obstetric and neonatal management, including new treatments such as antenatal magnesium sulphate or changes in delivery management such as delayed cord clamping and placental transfusion. We cover short and long term medical, psychological, and experiential consequences for individuals born extremely preterm, their mothers and families, as well as preventive measures that may reduce the incidence of extreme preterm birth.

Box 1: Key definitions
World Health Organization definitions relating to
preterm birthPreterm
- Birth at less than 37 weeks or 259 days' gestation
Moderate to late preterm
- Birth at $32-36$ completed weeks of gestation
Very preterm
- Birth before 32 completed weeks of gestation
Extremely preterm

- Birth before 28 completed weeks of gestation (up to and including 27 weeks and 6 days of gestation)

Low birth weight

- Birth weight of less than $2500 \mathrm{~g}$

Very low birth weight

- Birth weight of less than $1500 \mathrm{~g}$

Extremely low birth weight

- Birth weight of less than $1000 \mathrm{~g}$

\section{Rates of extreme preterm births, survival, and associated morbidities}

Estimates from vital statistics data suggest that globally between $9 \%$ and $12 \%$ of births occur before 37 weeks' gestation, resulting in around 14.84 million preterm births a year. Extreme preterm births constitute around $0.42 \%$ of all births. ${ }^{5}$ In the UK, where national data are audited through an annual confidential inquiry, 3982 births were recorded in 2019 as occurring at 22-27 weeks' gestation. These represent $0.55 \%$ of the 717864 total births recorded, excluding planned terminations of pregnancy. ${ }^{6}$

Accurate recent population data in other countries are limited, but population cohorts such as

EXPRESS-2 (Sweden, 2014-17) and EPIPAGE-2 (France, 2011) suggest that rates of extreme preterm birth have been stable in high income countries over the past 25 years. $^{78}$

\section{Perinatal survival in extreme preterm birth}

Perinatal survival has improved in recent years. In European countries, rates of stillbirth at 24 to 27 weeks' gestation fell between 2004 and 2015 from 0.97 to 0.70 per 1000 births. Below 24 weeks, rates have remained similar over time at 0.55 per 1000 births ( $95 \%$ confidence interval (CI) 0.40 to 0.70 ) in 2004 and 0.53 per 1000 births (95\% CI 0.41 to 0.66 ) in 2015. ${ }^{9}$ These trends are matched in the latest UK data. ${ }^{6}$ However, variability is seen between countries. ${ }^{6} 9$ For example, the rate of stillbirth at 24 to 27 weeks' gestation in England and Wales in 2015 was 1.31 (95\% CI 1.23 to 1.40 ), in Ireland it was 0.78 ( $95 \%$ CI 0.59 to 1.02), and in Finland 0.43 (95\% CI 0.29 to 0.64 ); below 24 weeks, rates in 2015 varied from 0.26 (95\% CI 0.16 to 0.41 ) in Ireland to 1.73 (95\% CI 1.54 to 1.94 ) in the Netherlands. ${ }^{9}$ This variation may result in part from differences in the definition of stillbirth ${ }^{10}$ (box 2) and recording of data, but even between countries with similar approaches, differences remain with no obvious reason why. ${ }^{9}$ Improvements over time in neonatal survival are described, ${ }^{6-8}$ albeit with marked variation between countries at different weeks of gestation (fig 1). ${ }^{4} \mathrm{~A}$ recent meta-analysis showed that survival at 18-36 
months among live born extremely preterm babies ranged from $7.3 \%$ (95\% CI 3.9 to 13.1 ) at 22 weeks to $90.1 \%$ (95\% CI 87.4 to 92.3 ) at 27 weeks. ${ }^{11}$ This appears to be primarily because of perinatal decision making: although high quality comparisons are limited, 4 management guidelines for extreme preterm birth vary substantially between countries. ${ }^{12}$ Variability in perinatal survival is also evident at regional ${ }^{13}$ and hospital levels. ${ }^{14}$

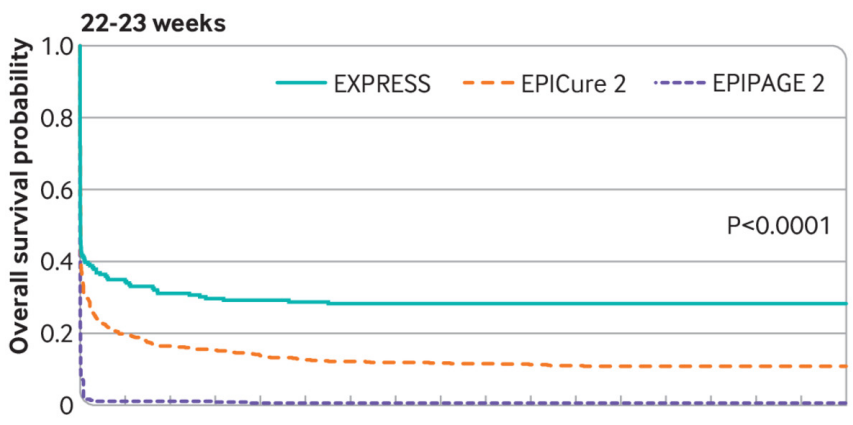

Risk table

EXPRESS
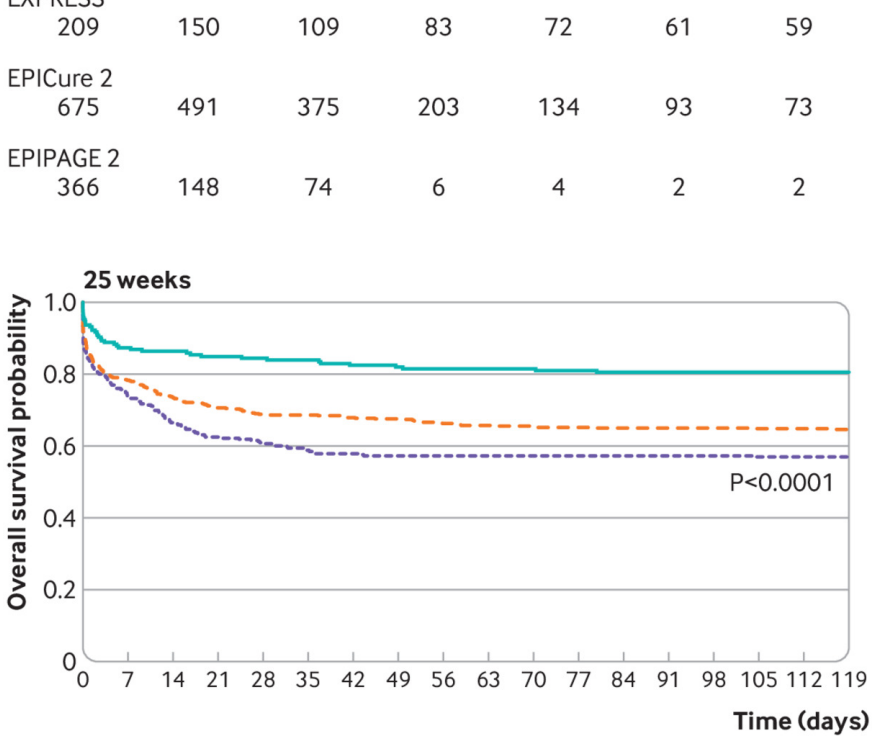

Risk table

EXPRESS

\begin{tabular}{|c|c|c|c|c|c|c|}
\hline 205 & 202 & 198 & 192 & 179 & 173 & 165 \\
\hline $\begin{array}{c}\text { EPICure } 2 \\
548\end{array}$ & 520 & 503 & 469 & 429 & 377 & 355 \\
\hline $\begin{array}{c}\text { EPIPAGE } 2 \\
325\end{array}$ & 307 & 296 & 272 & 240 & 198 & 185 \\
\hline $\begin{array}{c}\text { Fetuses } \\
\text { alive at } \\
\text { maternal } \\
\text { admission }\end{array}$ & $\begin{array}{l}\text { Live } \\
\text { births }\end{array}$ & $\begin{array}{c}\text { Survived } \\
\text { to } \\
1 \text { hour }\end{array}$ & $\begin{array}{c}\text { Survived } \\
\text { to } \\
24 \text { hours }\end{array}$ & $\begin{array}{c}\text { Survived } \\
\text { to } \\
7 \text { days }\end{array}$ & $\begin{array}{c}\text { Survived } \\
\text { to } \\
28 \text { days }\end{array}$ & $\begin{array}{c}\text { Survived } \\
\text { to } \\
16 \text { weeks }\end{array}$ \\
\hline
\end{tabular}

\section{Box 2: Stillbirth}

No agreed international definition of stillbirth exists, and the recording of fetal deaths at extreme preterm gestations varies by country. European recommendations are that all births from 22 weeks' gestational age should be officially recorded, ${ }^{10}$ but some countries define stillbirth using higher thresholds or birth weight. For example, stillbirth is defined as fetal death from 24 weeks in the UK and by the World Health Organization, 180 days in Italy, and 28 weeks in Bulgaria; in Austria, Belgium, Czech Republic, Germany, and Poland, fetal deaths are recorded at $500 \mathrm{~g}$ and above.

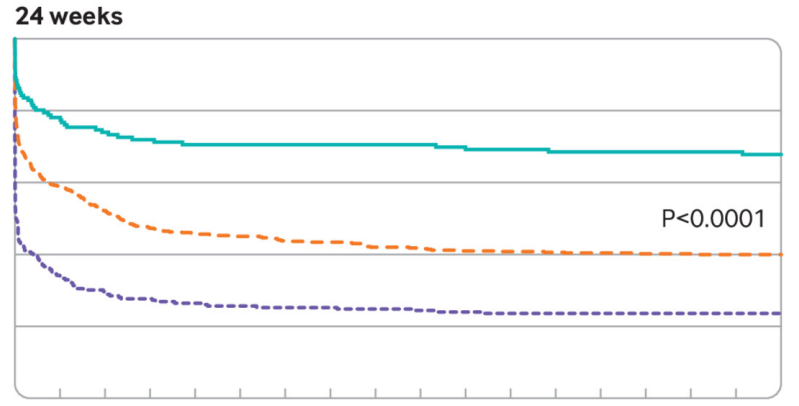

Risk table

EXPRESS

$\begin{array}{ccccccc}\begin{array}{c}\text { EXPRESS } \\ 146\end{array} & 144 & 133 & 123 & 114 & 103 & 100 \\ \begin{array}{c}\text { EPICure 2 } \\ 493\end{array} & 441 & 413 & 338 & 290 & 226 & 197 \\ \begin{array}{c}\text { EPIPAGE 2 } \\ 246\end{array} & 186 & 140 & 106 & 83 & 65 & 58\end{array}$

\section{6 weeks}

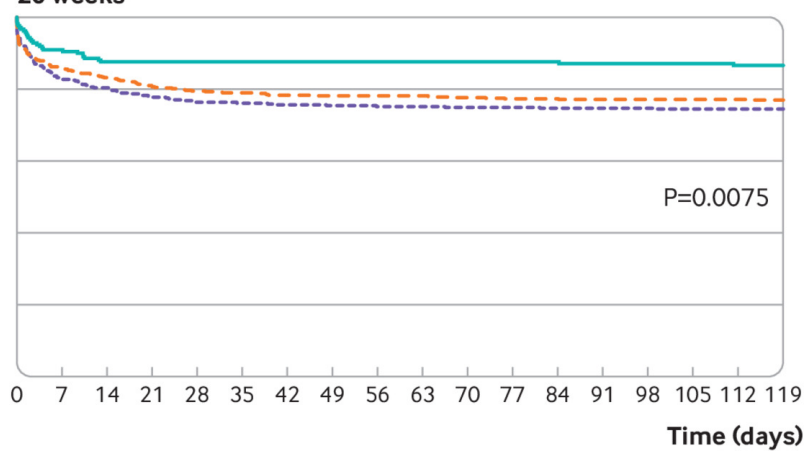

Risk table

\begin{tabular}{|c|c|c|c|c|c|c|}
\hline $\begin{array}{c}\text { EXPRESS } \\
209\end{array}$ & 207 & 206 & 202 & 190 & 183 & 181 \\
\hline $\begin{array}{c}\text { EPICure } 2 \\
594\end{array}$ & 580 & 573 & 543 & 510 & 472 & 458 \\
\hline $\begin{array}{c}\text { EPIPAGE } 2 \\
422\end{array}$ & 413 & 404 & 389 & 349 & 322 & 314 \\
\hline $\begin{array}{c}\text { Fetuses } \\
\text { alive at } \\
\text { maternal } \\
\text { admission }\end{array}$ & $\begin{array}{l}\text { Live } \\
\text { births }\end{array}$ & $\begin{array}{c}\text { Survived } \\
\text { to } \\
1 \text { hour }\end{array}$ & $\begin{array}{l}\text { Survived } \\
\text { to } \\
24 \text { hours }\end{array}$ & $\begin{array}{c}\text { Survived } \\
\text { to } \\
7 \text { days }\end{array}$ & $\begin{array}{c}\text { Survived } \\
\text { to } \\
28 \text { days }\end{array}$ & $\begin{array}{c}\text { Survived } \\
\text { to } \\
16 \text { weeks }\end{array}$ \\
\hline
\end{tabular}

Fig 1 | Survival for fetuses alive at maternal admission to hospital born at 22-23, 24, 25, and 26 weeks' gestation in national cohorts from Sweden (EXPRESS, 2004-07), England (EPICure-2, 2006), and France (EPIPAGE-2, 2011). Adapted from Morgan et al, $2021^{4}$

\section{Longer term morbidities}

Marked survival differences are not clearly related to longer term morbidities. ${ }^{4}$ Higher intensities of perinatal ${ }^{1314}$ and neonatal ${ }^{15}$ care are related to improved survival without increasing proportions of survivors with neurodevelopmental impairment at 1.5 to 2.5 years, suggesting that more aggressive treatment does not cause increased morbidity. Yet despite such differences and improvements in survival over time, results are more mixed for longer term 
neurological outcomes such as cognition, which have not improved in more recent cohorts. ${ }^{1617}$ Comparisons of children from the English EPICure (born in 1995) and EPICure-2 (born in 2006) cohorts at age 11 , for example, showed no improvement in moderate to severe disability (which affected 55\% of survivors born at 22-25 weeks' gestation in both cohorts using imputed data to account for loss to follow-up), with no change either in cognition (difference in mean mental processing index score $0.1,95 \%$ CI -0.3 to 0.5) ${ }^{18}$ Similarly, in three cohorts from the Victorian Infant Collaborative Study (VICS), Australia, from 1991-2, 1997, and 2005, average IQ was similar across the three cohorts. ${ }^{19}$ Postnatal environment is also likely important in modifying outcomes into childhood and later life. ${ }^{3}$ For example, a recent meta-analysis of European preterm cohorts showed that, compared with families where mothers had a bachelors or higher degree, standardised mean differences of cognitive scores for children born extremely preterm were 0.24 (95\% CI 0.02 to 0.46 ) lower in families where mothers had an upper secondary or short tertiary level of education, and 0.57 ( $95 \%$ CI 0.34 to 0.76 ) lower when mothers had only primary or lower secondary education. ${ }^{20}$

\section{Management options}

\section{Shared decision making and counselling}

Careful counselling is important to enable women and their families to be partners in clinical decision making. ${ }^{21}$ Appropriate consideration should be given to personal and religious beliefs, as well as social factors. ${ }^{22}$ Advice from practitioners outside the hospital environment who know the family may be helpful in reaching decisions.

Antenatally, counselling should cover risks to the mother as well as longer term outcomes affecting the child: more than a quarter of women in a recent study from a regional referral centre for extreme preterm birth experienced labour or delivery complications such as sepsis and haemorrhage. ${ }^{2}$ Predicting outcomes for children born extremely preterm is challenging, however. The child's long term prognosis is likely to change during the course of the neonatal hospitalisation, particularly if the child experiences major events such as severe brain injury or the need for surgery. ${ }^{23}$ Risks identified from population data must be adapted for an individual's situation, and perinatal management may also have changed substantially since longer term follow-up studies were initiated, meaning research outcomes are not fully reflective of current clinical practice.

\section{Obstetric management}

Best management practices in preparation for extreme preterm birth are shown in box 3. Magnesium sulphate infusion peripartum is advised, ${ }^{2425}$ and delayed cord clamping is now recommended when appropriate. ${ }^{24} 2627$ During preterm labour, cardiotocograph (CTG) monitoring of the fetal heart rate is difficult owing to frequent instances of signal loss associated with the small size of the fetus. Additionally, as the fetal autonomic nervous system is not mature, fetal heart rate patterns which may be typical at later gestations are not present. Only low quality evidence from small case control or cohort studies supports the use of CTG in preterm birth; no studies show benefit from monitoring specifically at extreme preterm gestations, however abnormal baseline variability and the presence of late, prolonged, and variable decelerations are associated with fetal hypoxia. ${ }^{24}$ Mode of delivery is more controversial. The one systematic review of randomised controlled trials (RCTs) for mode of delivery in extreme preterm birth is inconclusive. ${ }^{30}$ Caesarean section (box 3) may be indicated for maternal reasons (such as maternal haemorrhage) or fetal (such as severe fetal growth restriction), or where there is an agreed decision to resuscitate the neonate and labour would be detrimental to the outcome. Following delivery, delayed cord clamping facilitates placental transfusion to the newborn. "Milking" of the cord should be avoided as an RCT showed an association with a secondary outcome of increased intraventricular haemorrhage at extreme preterm gestations (risk difference $16 \%$, 95\% CI 6\% to $26 \%$ compared with delayed cord clamping alone). ${ }^{31}$ Delayed cord clamping is both well evidenced ${ }^{2829}$ and acceptable to parents, ${ }^{32}$ although may not always be appropriate, for example with placental abruption. ${ }^{33}$ Mobile resuscitation trolleys to facilitate bedside resuscitation with the umbilical cord intact are available and acceptable to parents. ${ }^{32} 34$

\section{Box 3: Recommendations for best practice obstetric management}

- Transfer the mother antenatally to a tertiary centre that can provide appropriate care to optimise outcome

- Tocolysis may be useful if it is safe for mother and baby to delay delivery short term and allow timely administration of antenatal corticosteroid treatment

- Administer antenatal corticosteroids to facilitate fetal lung maturation

- Provide peripartum magnesium sulphate infusion to reduce neurological injury (as recommended by the National Institute for Health and Care Excellence (NICE) in the UK and various professional societies) 2425

- Caesarean section is indicated for risks to the mother's life or when an agreement has been made to resuscitate the neonate and labour would be detrimental to outcome

- Perform delayed cord clamping of at least 60 seconds to facilitate placental transfusion to the newborn 24 26-29

\section{Neonatal management}

Babies may be offered compassionate (palliative, also known as "comfort focused") or survival focused ("active") care following delivery. If compassionate care is provided, care objectives are to avoid painful stimuli or maternal-infant separation. Advise parents that babies may show signs of life, but respiratory support should not be used. ${ }^{21}$ Conversely, most babies receiving active care are likely to require some form of respiratory support. Current evidence suggests early non-invasive continuous positive airway pressure (CPAP) is preferred to intubation and ventilation. This comes from a meta-analysis which showed that a combined outcome of death or bronchopulmonary dysplasia was reduced in infants of 24 to 31 weeks' gestation receiving CPAP (relative risk 0.90, 95\% CI 0.83 to o.98). 35 Transfer to the neonatal intensive care unit should follow stabilisation; parents should be able to accompany the baby, especially for inter-hospital transfer.

During hospitalisation, parent-baby closeness should be promoted, particularly through skin-to-skin contact as well as involvement in providing routine care such as feeds or nappy changes, as such closeness enhances neurobehavioural outcomes. Ward rounds led by parents provide valuable opportunities for this, and have recently been shown to be feasible. ${ }^{36}$ Optimal management of neonates is hugely debated, with many questions outstanding. These include if, when, and how exogenous surfactant therapy should be used. ${ }^{37}$ Similarly, early initiation of feeding is thought to decrease necrotising enterocolitis and late onset neonatal sepsis, but precise strategies relating to the quantity, frequency, and rate of increase of feeds still need to be determined. ${ }^{38}$ Debate also exists for other areas of neonatal management, including use of prophylactic antibiotics, management of a patent ductus arteriosus, and strategies for controlling pain and discomfort. Approaches to early developmental care, such as the Newborn Individualized Developmental Care and Assessment Program ${ }^{39}$ are increasingly 
used because of concerns about potential long term effects of the intensive care environment. ${ }^{40}$

\section{Challenges for children and their families}

Many children born extremely preterm have happy fulfilling lives, but they have an increased risk of a wide range of health, learning, and social difficulties compared with those born at higher gestational ages. ${ }^{41}$ Specialist follow-up with appropriate multidisciplinary input enables potential problems to be identified early and thus mitigates risks. This is an opportunity for the child and family that should not be missed, and primary care has a role in ensuring such follow-up is in place. Early intervention has been shown to improve cognitive and motor outcomes among all preterm infants, but specific evidence is lacking for the extreme preterm population. $4^{42}$

\section{Motor problems}

Motor development may be disrupted following extreme preterm birth, from minor delays in sitting or walking, to severe neuromotor impairment, such as cerebral palsy, which is the main motor disorder and affects around $10 \%$ to $20 \%$ of individuals born extremely preterm. ${ }^{1843-45}$ Rates of cerebral palsy have remained relatively stable over time in cohort studies of children born extremely preterm (for example, at age 8 they were $13 \%, 11 \%$, and $14 \%$ in the $1991-92,1997$, and 2005 VICS cohorts, respectively) ${ }^{1819}$; however, findings from a study of registries that included nearly all children with cerebral palsy in Victoria, Australia ${ }^{45}$ indicate that cerebral palsy rates have decreased from 102.5 per 1000 neonatal survivors in 1992-2000 to 70.6 per 1000 in 2001-2009. Hence, findings for temporal trends in cerebral palsy among children born extremely preterm are conflicting, which may be partly attributable to the variety of assessment tools used (making comparison difficult) or other methodological issues (eg, differences in baseline populations, outcome definitions, ages at assessment, or follow-up rates). ${ }^{3}$

Regarding motor problems without cerebral palsy, such as deficits in coordination, balance, gross and fine motor control (also referred to as developmental coordination disorder, DCD), evidence from the VICS study show that rates of DCD have increased over time, with a respective prevalence of $13 \%, 15 \%$, and $26 \%$ for extreme preterm babies born in 1991-92, 1997, and 2005. ${ }^{17}$

\section{Cognitive and academic performance}

Meta-analyses of childhood IQ show that children born extremely preterm score on average 11 to 13 IQ points lower than term born children. ${ }^{4647}$ No evidence of improvement in mean difference in IQ is seen over time, ${ }^{47}$ nor of developmental catch-up by individuals as they grow older. ${ }^{19}$ For example, children in the EPICure cohort had IQ assessed at 2.5, 5, 6, and 19 years; deficits remained stable throughout follow-up. ${ }^{48}$ Children born extremely preterm are more likely to have poorer academic achievement in several areas, including maths, reading, and spelling, ${ }^{46}$ and this may persist throughout their schooling. ${ }^{46} 47$ Such findings indicate that these children may need additional educational support to boost their learning.

\section{Mental health and social interactions}

Findings from a systematic review and meta-analysis which included summary data on mental outcomes from 41 studies show that children born extremely preterm are more likely to experience attention deficit/hyperactivity disorder (ADHD), internalising problems (eg, anxiety, depression), difficulties with social interaction, and are more likely to have autistic characteristics than their peers born at term. ${ }^{49}$ The size of these associations varied between moderate (internalising problems, social problems, autistic characteristics) to large (ADHD, which is four times more likely in extremely preterm children than in term born peers ${ }^{50}$ ) in childhood. Overall, children born extremely preterm struggle more with social interaction, tend to be shyer, have fewer friends, are more socially withdrawn, ${ }^{51}$ and are more likely to be bullied than term born peers. ${ }^{5253}$ The prevalence of autistic spectrum disorders is $8 \%$ higher among those born extremely preterm compared with term born children, ${ }^{54}$ with persistence of increased autistic traits through to early adulthood. ${ }^{55}$ Although children born extremely preterm are at increased risk of psychiatric disorders, ${ }^{56}$ this does not mean that individuals will necessarily develop mental problems-only that the risk is higher when compared with those born at term. Evidence suggests that ADHD and internalising symptoms persist into adulthood, ${ }^{49}$ but clinical diagnoses of disorders seem to reduce, ${ }^{57}$ suggesting that adults who were born extremely preterm may overcome earlier mental health problems.

\section{How do early life circumstances affect adults born extremely preterm?}

Recent meta-analyses show that adults born preterm have greater risks of socioeconomic problems than adults born at term. Risks increase with decreasing gestational age. For example, adults born extremely preterm were $67 \%$ less likely to be in a relationship and $69 \%$ less likely to be parents than adults born at term ${ }^{58}$; they also had fewer educational qualifications, lower employment rates, and were more frequently in receipt of social benefits. ${ }^{59}$ Furthermore, indicators of lower wealth and poorer social relationships were found at different ages and in both sexes, suggesting they are persistent and that difficulties found in childhood can contribute to social and economic inequalities in adulthood. Figure 2 shows approximate effect sizes ${ }^{60}$ for the impact of very preterm birth $(<32$ weeks' gestation-but relative differences are very similar among adults born extremely preterm) on the social and wealth outcomes reported in these meta-analyses, which included summary data from more than 20 international studies and Nordic population registries..$^{41}$ Cross generational fertility loss can be another consequence: as well as adults born preterm being less likely to become parents, women delivering extremely preterm are less likely to have further children. ${ }^{61}$ Little evidence exists on how best to tackle these problems, but it is important to encourage early social interaction and to provide educational support. Extreme preterm birth may also affect other aspects of physical health, such as respiratory or cardiovascular function and risk for metabolic disease, ${ }^{6263}$ but these problems are as yet poorly understood. 


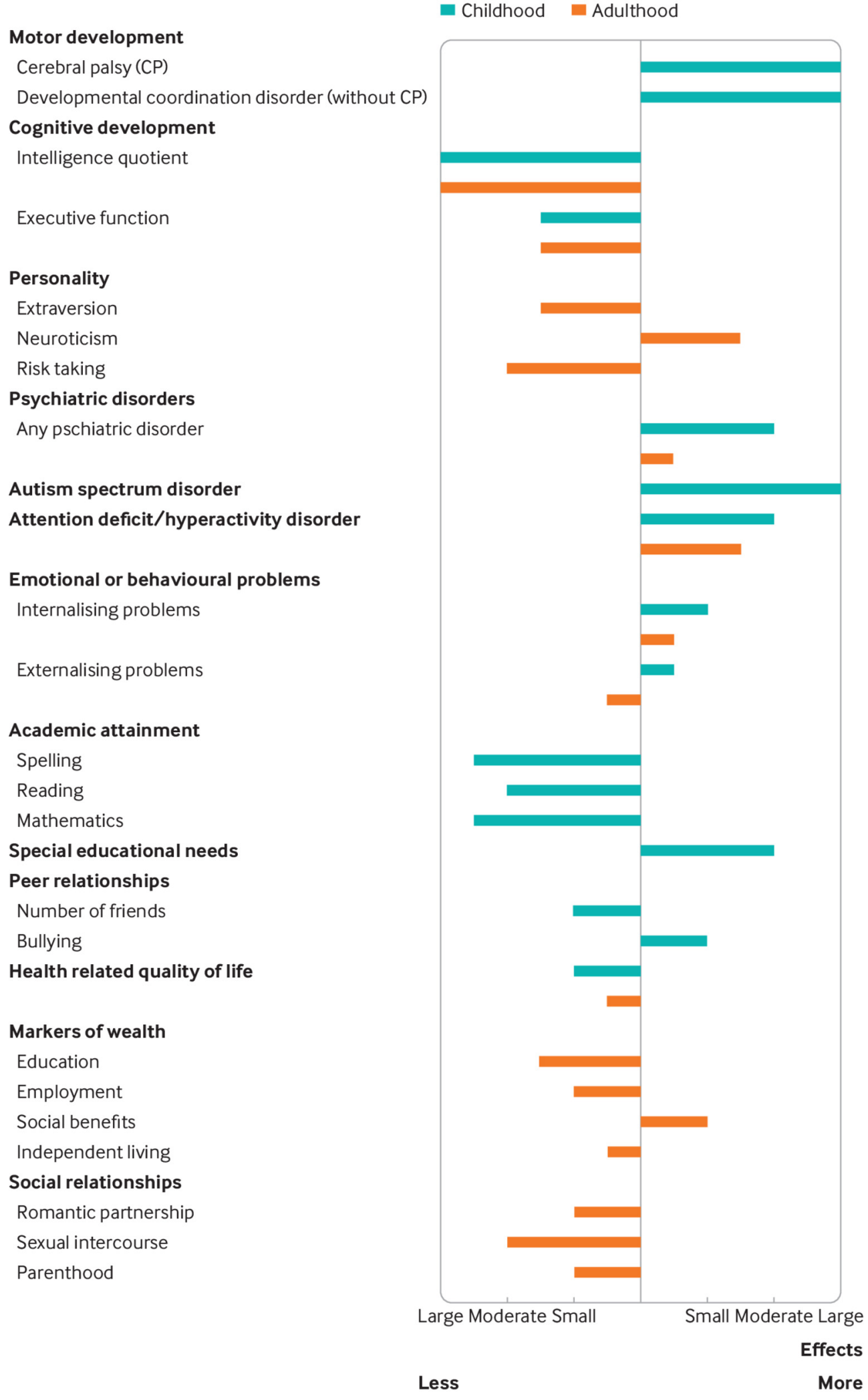

Fig 2 | Approximate effect sizes for the impact of very preterm birth («32 weeks' gestation) on long term outcomes (compared with birth at term; zero vertical line). Effect sizes are defined as small (odds ratio (OR) 1.48 or inverted 0.67; Cohen's d between means 0.2), moderate (OR 3.45 or 0.29, Cohen's d 0.5), or large (OR 9.00 or 0.11,

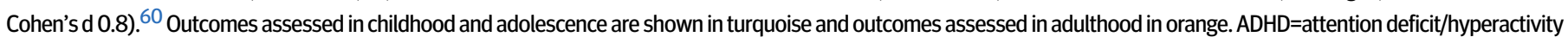
disorder; $\mathrm{ASD}=$ autism spectrum disorder; $\mathrm{DCD}=$ developmental coordination disorder; $\mathrm{HRQ}$ L=health related quality of life; IQ=intelligence quotient; $\mathrm{SEN}=$ special educational needs. Figure and caption adapted from Wolke et al, $2019^{41}$ 


\section{What are the consequences of extreme preterm birth for parents?}

In women who deliver extremely preterm, and particularly in those who give birth by caesarean, risks include haemorrhage, infection, and admission to the intensive care unit. ${ }^{264} \mathrm{~A}$ midline uterine incision or "classic" caesarean section, which has a higher chance of scar dehiscence in subsequent labours than lower segment caesarean section, is more frequently performed, and women are therefore advised against having future vaginal deliveries. Pregnancy related conditions that are associated with extreme preterm birth are also associated with increased risks of disease in the mother. Women with pre-eclampsia are twice as likely to be diagnosed with cardiovascular disease or stroke as women with uncomplicated pregnancies, and approximately half of women with gestational diabetes mellitus develop type 2 diabetes within 10 years. $^{65}$

Extreme preterm birth is stressful for both parents; this may be exacerbated by operative birth that may require long recovery and a lack of contact with the baby after birth. Early psychological support may allow parents to participate more fully in shared decision making. After an extreme preterm birth, parents may seek answers about the cause of their baby's early delivery, often inappropriately blaming themselves. Debriefing from healthcare professionals with specialised knowledge and with access to results of placental histopathology and details of any vaginal infection is recommended, particularly to plan management of any future pregnancy. Following second trimester pregnancy loss (16 to 27 weeks' gestation), recurrent second trimester delivery is around $7 \%,{ }^{66}$ and the risk of any preterm birth around $25-35 \% .{ }^{67}$ Anxiety, depression, post-traumatic stress disorder, and poorer overall wellbeing are increased in mothers and fathers, ${ }^{68}$ with effects persisting for many years. ${ }^{69}$ However, extreme preterm birth alone does not seem to have a direct impact on relationships; higher rates of relationship breakdown that occur among parents of surviving children seem to be related to poor neurodevelopmental outcomes of the child. ${ }^{7}$

\section{Prevention of preterm birth}

Prevention begins before pregnancy in community and public health efforts: a woman who is healthy at conception is more likely to have a successful pregnancy and a healthy child. Socioeconomic circumstances (eg, deprivation ${ }^{71}$ ) and environmental risks (eg, air pollution $^{72}$ ) are associated with increased risk of extremely preterm birth. Societal measures include legislation to make air free of cigarette smoke, a measure associated with reductions in preterm birth rates of $10.4 \%$ (95\% CI 2.0 to 18.8$).{ }^{73}$ Advice for women is shown in box 4. Paternal health is also important: obesity is linked with preterm birth and other adverse pregnancy outcomes. ${ }^{83}$

\section{Box 4: Prevention of preterm birth}

- Both partners should stop smoking; even smoking cessation during pregnancy protects against preterm birth. ${ }^{74}$ Behavioural interventions for smoking cessation during pregnancy are effective, but evidence for the efficacy of drugs or nicotine replacement therapy is limited. 75

- Optimise care of existing maternal medical diseases such as hypertension, diabetes and thyroid disorders.

- Advise on healthy diet and exercise as being underweight or overweight increases the risk of complications including congenital anomalies, pre-eclampsia and small for gestational age, all of which may contribute to extreme preterm delivery. ${ }^{76}$
- Advise women before conceiving to reduce alcohol and caffeine consumption, stop recreational drugs, take folic acid, and ensure adequate vitamin $\mathrm{D}$ intake. ${ }^{77}$

- Screen for sexually transmitted infection in higher risk women as these are associated with preterm birth. ${ }^{78}$

- Consider mid-stream urine culture (MSU) in early pregnancy as asymptomatic urinary tract infection and pyelonephritis is associated with preterm birth. 79

- Low dose aspirin begun before 16 weeks of gestation reduces the risk of pre-eclampsia, fetal growth restriction and associated preterm birth. ${ }^{80} 81$

- Other interventions to reduce preterm birth include vaginal progestogen $^{82}$ and cervical cerclage.

\section{Education into practice}

- How does your practice signpost women and families who have experienced extreme preterm birth to multi-agency support?

- Think about a family in your practice that has been affected by extreme preterm birth; what challenges do you think they might experience?

- What do you know about the birth circumstances of child and adult patients in your practice who experience problems potentially related to extreme preterm birth?

\section{Questions for future research}

- RECAP Preterm (https://recap-preterm.eu/). The "Research on European Children and Adults born Preterm" project is funded by the European Union's Horizon 2020 research and innovation programme and aims to improve the health, development, and quality of life of children and adults born very preterm or very low birth weight by developing the RECAP Preterm cohort platform. This is a sustainable, geographically diverse, and multidisciplinary database of national and European cohorts of babies born very preterm or at very low birth weight constituted over a 40 year time span. The platform is designed to optimise the use of population data for research and innovation in healthcare, social, and education policy

- APIC (https://www.apic-preterm.org/). The "Adults born Preterm International Collaboration" is a group of researchers who collaborate on individual patient data meta-analyses to investigate outcomes in adulthood of those who were born preterm

- CASSAVA study (https://www.ed.ac.uk/centre-reproductivehealth/cassava/about-the-cassava-study). This project is investigating whether vaginal or caesarean delivery is safer for women with threatened preterm delivery. Researchers are working with women and medical staff to identify whether further research on this topic is feasible

- The impact of the SARS-CoV-2 pandemic on extremely preterm birth is not yet fully understood. A number of studies have suggested that public health measures implemented at regional and national levels, such as curfews or lockdowns, were associated with reduced numbers of extreme preterm births. The international Perinatal Outcomes in the Pandemic study (https://www.ipopstudy.com/) is a collaborative international team of scientists investigating this question

\section{Additional educational resources}

- The British Association of Perinatal Medicine has produced guidance for healthcare professionals relating to extremely preterm birth (https://www.bapm.org/resources/80-perinatal-management-of-extreme-preterm-birth-before-27-weeks-of-gestation-2019)

- A comprehensive review of childhood and adulthood outcomes The Life Course Consequences of Very Preterm Birth was published in the 
Annual Review of Developmental Psychology in December 2019..$^{11}$ Another comprehensive review, School-aged neurodevelopmental outcomes for children born extremely preterm, was published in the Archives of Disease in Childhood in May $2021^{19}$

- The European Foundation for the Care of Newborn Infants (https://www.efcni.org) is a pan-European organisation bringing together families, healthcare professionals, and researchers, working together to ensure the best start in life for every baby. EFCNI has coordinated the development of the European Standards for Newborn Health covering 11 different areas of health (https://newborn-healthstandards.org/) by topic experts to ensure that care for preterm and sick babies is harmonised across countries

- The PRISM website (Premature infants' skills in mathematics, https://www.nottingham.ac.uk/helm/dev/prism/) provides a free selection of e-learning resources aimed at teachers but also suitable for other professionals who may be involved in supporting children born preterm

\section{Information resources for parents}

- The International Stillbirth Alliance (https://www.stillbirthalliance.org) aims to raise awareness and promote global collaboration for the prevention of stillbirth and newborn death, and provision of appropriate respectful care for all those affected. The alliance provides free information online and partners with support groups in Italy, Spain, the UK, and US

- The Stillbirth and Neonatal Death charity, Sands (https://www.sands.org.uk/), is a UK member of the International Stillbirth Alliance. It supports anyone affected by the death of a baby, and works with professionals and researchers to reduce the number of babies dying

- Tommys (https://www.tommys.org/) is a UK organisation that funds research into miscarriage, stillbirth, and preterm birth. It also provides a pregnancy information service that includes information and consultancy in cases of loss, and also for parents-to-be to help them have a healthy pregnancy and baby

- The European Foundation for Care of the Newborn Infant (https://www.efcni.org) works to represent the voice of preterm babies and their families, and provides freely accessible, current and evidence based information written in easy-to-understand language by health experts together with patient representatives. The site provides comprehensive information and material on pregnancy, time in the neonatal intensive care unit (key facts about preterm birth, health conditions, breastfeeding, role of parents), discharge, and growing up. In almost every country, national and local organisations support parents of preterm children and provide free information online. The EFCNI homepage provides a list of partnering national parent organisations

- Bliss (https://www.bliss.org.uk/) is a UK based charity that aims to give preterm and sick babies the best start in life. It provides direct support and help to individual families across the UK. The website contains lots of information relating to emotional and practical support, parental wellbeing and mental health, and financial information, as well as links to other organisations that can provide more focused support (eg, relating to bereavement, or for specific disabilities)

\section{How patients were involved in the creation of this article}

None of the authors are patients. Nicole Thiele is Vice Chair of the Executive Board of the European Foundation for Care of the Newborn Infant, the first pan-European organisation and network to represent the interests of preterm and newborn infants and their families. The board consists of three members, and represents and conducts the day-to-day business of the Foundation. Nicole works closely with the 10 member parent board, who support EFCNI with their knowledge and experience from parenting preterm babies and from their work for national parent organisations in their home countries. Nicole also has family who experienced the consequences of an extremely preterm birth nearly 50 years ago; she is personally committed to driving forward the prevention of preterm birth, the continuous improvement of treatment and care, and the philosophy of family centred developmental care and parental involvement, to give every baby the best start in life. The manuscript was shown to parents who have experienced extreme preterm birth once we had finalised the first draft. For this, we are extremely grateful to Mandy Daly (Irish Neonatal Health Alliance, Ireland), Livia Nagy-Bonnard (Melletted a helyem Egyesület, Hungary), and Estela Counho (XXS, Portugal).

\section{How this article was created}

References used in this article were identified from the personal archives of the contributing authors, each of whom has specific and complementary expertise related to the topic of extreme preterm birth. We also performed searches in PubMed using the terms "preterm birth" and "extreme preterm" to ensure we had the most recent evidence available. ASM contributed neonatal and epidemiological knowledge, NT provided a perspective from families and children affected by extremely preterm birth, MM has worked extensively as a psychologist studying the long term effects of extremely preterm birth, and ALD provided expertise relating to obstetric and preventive care of women at risk of extreme preterm birth.

Contributorship statement: ASM conceived the idea for this article and organised the collaboration between participating authors. ASM, NT, and ALD were involved in drafting the original proposal. All authors were involved in identifying sources and writing the initial draft, with ASM editing contributions and coordinating revisions to which all authors contributed. All authors read and approved the final draft. ASM is guarantor for the overall content.

This article is available as open access (as part of the grant agreement for RECAP Preterm) under a CC-BY-NC licence.

Competing interests: We have read and understood The BM/policy on declaration of interests and declare that we have no competing interests.

Funding: ASM, MM, and NT are supported by funding from the European Union's Horizon 2020 Research and Innovation Program RECAP Preterm Project (grant no. 733280). ALD is supported by the National Institute for Health Research University College London Hospitals Biomedical Research Centre.

Provenance and peer review: commissioned, based on an idea from the author; externally peer reviewed

World Health Organization. Preterm birth factsheet. 2018. https://www.who.int/news-room/factsheets/detail/preterm-birth.

Morgan AS, Waheed S, Gairee S, Marlow N, David AL. Maternal and infant morbidity following birth before 27 weeks of gestation: a single centre study. Sci Rep 2021;11:288.

doi: 10.1038/s41598-020-79445-1 pmid: 33431902

Torchin H, Morgan AS, Ancel P-Y. International comparisons of neurodevelopmental outcomes in infants born very preterm. Semin Fetal Neonatal Med 2020;25:101109.

doi: 10.1016/j.siny.2020.101109 pmid: 32354556

4 Morgan AS, Zeitlin J, Kallen K, etalBirth outcomes between 22-26 weeks' gestation in national population-based cohorts from Sweden, England and France. Acta Paediatrica 2021;00:1-17doi: 10.1111/apa.16084

Chawanpaiboon S, Vogel JP, Moller A-B, etal. Global, regional, and national estimates of levels of preterm birth in 2014: a systematic review and modelling analysis. Lancet Glob Health 2019;7:e37-46. doi: 10.1016/S2214-109X(18)30451-0 pmid: 30389451

6 Draper ES, Gallimore ID, Smith LK, etal. MBRRACE-UK perinatal mortality surveillance report: UK perinatal deaths for births from January to December 2019. The Infant Mortality and Morbidity Studies, 2021

Norman M, Hallberg B, Abrahamsson T, etal. Association between year of birth and 1-year survival among extremely preterm infants in Sweden during 2004-2007 and 2014-2016. JAMA 2019;321:1188-99. doi: 10.1001/jama.2019.2021 pmid: 30912837

8 Ancel P-Y, Goffinet F, Kuhn P, etalEPIPAGE-2 Writing Group. Survival and morbidity of preterm children born at 22 through 34 weeks' gestation in France in 2011: results of the EPIPAGE-2 cohort study. JAMA Pediatr 2015:169:230-8.

doi: 10.1001/jamapediatrics.2014.3351 pmid: 25621457

Smith LK, Hindori-Mohangoo AD, Delnord M, etal. Quantifying the burden of stillbirths before 28 weeks of completed gestational age in high-income countries: A population-based study of 19 European countries. 2018:392:1639-46.

10 Smith LK, Blondel B, Zeitlin JEuro-Peristat Scientific Committee. Producing valid statistics when legislation, culture and medical practices differ for births at or before the threshold of survival: report of a European workshop. BJOG 2020;127:314-8.

doi: 10.1111/1471-0528.15971 pmid: 31580509 
11 Myrhaug HT, Brurberg KG, Hov L, Markestad T. Survival and impairment of extremely premature infants: A meta-analysis. Pediatrics 2019;143:e20180933. doi: 10.1542/peds.2018-0933 pmid: 30705140

12 Gallagher K, Martin J, Keller M, Marlow N. European variation in decision-making and parental involvement during preterm birth. Arch Dis Child Fetal Neonatal Ed 2014;99:F245-9. doi: 10.1136/archdischild-2013-305191 pmid: 24554563

13 Serenius F, Blennow M, Maršál K, Sjörs G, Källen KEXPRESS Study Group. Intensity of perinatal care for extremely preterm infants: outcomes at 2.5 years. Pediatrics 2015;135:e1163-72. doi: 10.1542/peds.2014-2988 pmid: 25896833

14 Morgan AS, Foix L'Helias L, Diguisto C, etal. Intensity of perinatal care, extreme prematurity and sensorimotor outcome at 2 years corrected age: evidence from the EPIPAGE-2 cohort study. BMC Med 2018;16:227. doi: 10.1186/s12916-018-1206-4 pmid: 30514388

15 Rysavy MA, Li L, Bell EF, etalEunice Kennedy Shriver National Institute of Child Health and Human Development Neonatal Research Network. Between-hospital variation in treatment and outcomes in extremely preterm infants. N Engl J Med 2015;372:1801-11. doi: 10.1056/NEJMoa1410689 pmid: 25946279

16 Cheong JLY, Anderson PJ, Burnett AC, etalVictorian Infant Collaborative Study Group. Changing neurodevelopment at 8 years in children born extremely preterm since the 1990s. Pediatrics 2017;139:e20164086. doi: 10.1542/peds.2016-4086 pmid: 28814550

17 Spittle AJ, Cameron K, Doyle LW, Cheong JLVictorian Infant Collaborative Study Group. Motor impairment trends in extremely preterm children: 1991-2005. Pediatrics 2018;141:3410. doi: 10.1542/peds.2017-3410 pmid: 29567814

18 Marlow N, Ni Y, Lancaster R, etal. No change in neurodevelopment at 11 years after extremely preterm birth. Arch Dis Child Fetal Neonatal Ed 2021;106:418-24. doi: 10.1136/archdischild-2020-320650 pmid: 33504573

19 Doyle LW, Spittle A, Anderson PJ, Cheong JLY. School-aged neurodevelopmental outcomes for children born extremely preterm. Arch Dis Child 2021;106:834-8 doi: 10.1136/archdischild-2021-321668 pmid: 34035035

20 Sentenac M, Benhammou V, Aden U, etalMaternal education and cognitive development in 15 European very-preterm birth cohorts from the RECAP Preterm platform. Int J Epidemiol 2021. doi: 10.1093/ije/dyab170

21 Mactier $\mathrm{H}$, Bates SE, Johnston T, etal. Perinatal management of extreme preterm birth before 27 weeks of gestation: A framework for practice. 2020;105:232-9.

22 Oehmke F, Lauer T, Baecker J, etal. Ethical, legal, and religious aspects at the border of viability. Front Pediatr 2019;7:175. doi: 10.3389/fped.2019.00175 pmid: 31139602

23 Cheong JLY, Lee KJ, Boland RA, etalVictorian Infant Collaborative Study Group. Changes in long-term prognosis with increasing postnatal survival and the occurrence of postnatal morbidities in extremely preterm infants offered intensive care: a prospective observational study. Lancet Child Adolesc Health 2018;2:872-9. doi: 10.1016/S2352-4642(18)30287-6 pmid: 30361130

24 National Institute for Health and Care Excellence. Preterm labour and birth (NICE guideline [NG25]). 2019. https://www.nice.org.uk/guidance/ng25.

25 Jayaram PM, Mohan MK, Farid I, Lindow S. Antenatal magnesium sulfate for fetal neuroprotection: a critical appraisal and systematic review of clinical practice guidelines. J Perinat Med 2019;47:262-9. doi: 10.1515/jpm-2018-0174 pmid: 30352042

26 Delayed umbilical cord clamping after birth: ACOG committee opinion summary, number 814. Obstet Gynecol 2020;136:1238-9. doi: 10.1097/AOG.0000000000004168 pmid: 33214527

27 National Institute for Clinical Excellence. 2020 surveillance of preterm labour and birth (NICE guideline NG25). 2020. https://www.nice.org.uk/guidance/ng25/resources/2020-surveillanceof-preterm-labour-and-birth-nice-guideline-ng25-8772684877/chapter/Surveillance-decision?tab=evidence.

28 Tarnow-Mordi W, Morris J, Kirby A, etalAustralian Placental Transfusion Study Collaborative Group. Delayed versus immediate cord clamping in preterm infants. N Engl / Med 2017;377:2445-55. doi: 10.1056/NEJMoa1711281 pmid: 29081267

29 Duley L, Dorling J, Pushpa-Rajah A, etalCord Pilot Trial Collaborative Group. Randomised trial of cord clamping and initial stabilisation at very preterm birth. Arch Dis Child Fetal Neonatal Ed 2018;103:F6-14. doi: 10.1136/archdischild-2016-312567 pmid: 28923985

30 Alfirevic Z, Milan SJ, Livio S. Caesarean section versus vaginal delivery for preterm birth in singletons. Cochrane Database Syst Rev 2013;9:CD000078. doi: 10.1002/14651858.CD000078.pub3 pmid: 24030708

31 Katheria A, Reister F, Essers J, etal. Association of umbilical cord milking vs delayed umbilical cord clamping with death or severe intraventricular haemorrhage among preterm infants. JAMA 2019;322:1877-86. doi: 10.1001/jama.2019.16004 pmid: 31742630

32 Katheri AC, Sorkhi SR, Hassen K, etal.Acceptability of bedside resuscitation with intact umbilical cord to clinicians and patients' families in the United States. Front Paediatr 2018;6:100doi: 10.3389/fped.2018.00100

33 Meyer MP, Nevill E. Optimizing cord clamping in preterm infants: One strategy does not fit all. Front Pediatr 2019;7:46. doi: 10.3389/fped.2019.00046 pmid: 30873393

34 Weeks AD, Watt P, Yoxall CW, etal. Innovation in immediate neonatal care: development of the Bedside Assessment, Stabilisation and Initial Cardiorespiratory Support (BASICS) trolley. BMJ Innov 2015;1:53-8. doi: 10.1136/bmjinnov-2014-000017 pmid: 26191414

35 Schmölzer GM, Kumar M, Pichler G, Aziz K, O’Reilly M, Cheung PY. Non-invasive versus invasive respiratory support in preterm infants at birth: systematic review and meta-analysis. BMJ 2013;347:55980
36 Rackham O. Parent-led ward rounds. 2019. https://www.leosneonatal.org/neonatal-mental-healthawareness-week/neonatal-mental-health-awareness-week-2019/best-practice/oliver-rackhamneonatal-consultant-parent-led-ward-rounds/.

37 DeMauro SB, Jensen EA. Evolving respiratory care of the preterm infant. 2021;175:1004-5.

38 Kwok TC, Dorling J, Gale C. Early enteral feeding in preterm infants. Semin Perinatol 2019;43:151159. doi: 10.1053/..semperi.2019.06.007 pmid: 31443906

39 Als H, McAnulty GB. The Newborn Individualized Developmental Care and Assessment Program (NIDCAP) with Kangaroo Mother Care (KMC): Comprehensive Care for Preterm Infants. Curr Womens Health Rev 2011;7:288-301. doi: 10.2174/157340411796355216 pmid: 25473384

40 Soni R, Tscherning Wel-Wel C, Robertson NJ. Neuroscience meets nurture: Challenges of prematurity and the critical role of family-centred and developmental care as a key part of the neuroprotection care bundle. 2021. doi: 10.1136/archdischild-2020-319450

41 Wolke D, Johnson S, Mendonça M. The life course consequences of very preterm birth. Ann Rev Develop Psychol 2019;1:69-92doi: 10.1146/annurev-devpsych-121318-084804

42 Spittle A, Orton J, Anderson PJ, Boyd R, Doyle LW. Early developmental intervention programmes provided post hospital discharge to prevent motor and cognitive impairment in preterm infants. Cochrane Database Syst Rev 2015;(11):CD005495. doi: 10.1002/14651858.CD005495.pub4 pmid: 26597166

43 Pierrat V, Marchand-Martin L, Marret S, etalEPIPAGE-2 writing group. Neurodevelopmental outcomes at age 5 among children born preterm: EPIPAGE-2 cohort study. BMJ2021;373:n741. doi: 10.1136/bmj.n741 pmid: 33910920

44 Hafström M, Källén K, Serenius F, etal. Cerebral palsy in extremely preterm infants. Pediatrics 2018;141:20171433. doi: 10.1542/peds.2017-1433 pmid: 29222398

45 Reid SM, Meehan E, McIntyre S, Goldsmith S, Badawi N, Reddihough DSAustralian Cerebral Palsy Register Group. Temporal trends in cerebral palsy by impairment severity and birth gestation. Dev Med Child Neurol 2016;58(Suppl 2):25-35. doi: 10.1111/dmcn.13001 pmid: 26762733

46 Allotey J, Zamora J, Cheong-See F, etal. Cognitive, motor, behavioural and academic performances of children born preterm: a meta-analysis and systematic review involving 64061 children. BJOG 2018;125:16-25. doi: 10.1111/1471-0528.14832 pmid: 29024294

47 Twilhaar ES, Wade RM, de Kieviet JF, etal. Cognitive outcomes of children born extremely or very preterm since the 1990 s and associated risk factors: A meta-analysis and meta-regression 2018;172:361-7.

48 Linsell L, Johnson S, Wolke D, etal. Cognitive trajectories from infancy to early adulthood following birth before 26 weeks of gestation: a prospective, population-based cohort study. Arch Dis Child 2018;103:363-70. doi: 10.1136/archdischild-2017-313414 pmid: 29146572

49 Mathewson KJ, Chow CHT, Dobson KG, Pope El, Schmidt LA, Van Lieshout RJ. Mental health of extremely low birth weight survivors: A systematic review and meta-analysis. Psychol Bull 2017;143:347-83. doi: 10.1037/bul0000091 pmid: 28191983

50 Franz AP, Bolat GU, Bolat H, etal. Attention-deficit/hyperactivity disorder and very preterm/very low birth weight: a meta-analysis. Pediatrics 2018;141:e20171645.

51 Ritchie K, Bora S, Woodward LJ. Peer relationship outcomes of school-age children born very preterm. J Pediatr 2018;201:238-44. doi: 10.1016/j.jpeds.2018.05.034 pmid: 29958672

52 Day KL, Van Lieshout RJ, Vaillancourt T, Saigal S, Boyle MH, Schmidt LA. Peer victimization in extremely low birth weight survivors. Clin Pediatr (Phila) 2015;54:1339-45. doi: 10.1177/0009922815580770 pmid: 25857727

53 Wolke D, Baumann N, Strauss V, Johnson S, Marlow N. Bullying of preterm children and emotional problems at school age: cross-culturally invariant effects. J Pediatr 2015;166:1417-22. doi: 10.1016/j.jpeds.2015.02.055 pmid: 25812780

54 Johnson S, Hollis C, Kochhar P, Hennessy E, Wolke D, Marlow N. Autism spectrum disorders in extremely preterm children. J Pediatr 2010;156:525-31.e2 doi: 10.1016/j.jpeds.2009.10.041 pmid: 20056232

55 O'Reilly H, Ni Y, Johnson S, Wolke D, Marlow N. Extremely preterm birth and autistic traits in young adulthood: the EPICure study. Mol Autism 2021;12:30. doi: 10.1186/s13229-021-00414-0 pmid: 33957985

56 Johnson S, Marlow N. Preterm birth and childhood psychiatric disorders. Pediatr Res 2011;69:11R-8R. doi: 10.1203/PDR.0b013e318212faa0 pmid: 21289534

57 Johnson S, O’Reilly H, Ni Y, Wolke D, Marlow N. Psychiatric symptoms and disorders in extremely preterm young adults at 19 years of age and longitudinal findings from middle childhood. J Am Acad Child Adolesc Psychiatry 2019;58:820-826.e6. doi: 10.1016/j.jaac.2019.02.020 pmid: 31009655

58 Mendonça M, Bilgin A, Wolke D. Association of preterm birth and low birth weight with romantic partnership, sexual intercourse, and parenthood in adulthood: A systematic review and meta-analysis. JAMA Netw Open 2019;2:e196961. doi: 10.1001/jamanetworkopen.2019.6961 pmid: 31298716

59 Bilgin A, Mendonca M, Wolke D. Preterm birth/low birth weight and markers reflective of wealth in adulthood: A meta-analysis. Paediatrics. 2018;142; 20173625.

60 Chen $\mathrm{H}$, Cohen P, Chen S. How big is a big odds ratio? Interpreting the magnitudes of odds ratios in epidemiological studies. Commun Stat Simul Comput 2010;39:860-4doi: 10.1080/03610911003650383.

61 Alenius S, Kajantie E, Sund R, etal. The missing siblings of infants born preterm. Pediatrics 2018;141:1354. doi: 10.1542/peds.2017-1354 pmid: 29247118

62 Hurst JR, Beckmann J, Ni Y, etal. Respiratory and cardiovascular outcomes in survivors of extremely preterm birth at 19 years. Am J Respir Crit Care Med 2020;202:422-32. doi: 10.1164/rccm.202001-00160C pmid: 32302489 
63 Ni Y, Beckmann J, Hurst JR, Morris JK, Marlow N. Size at birth, growth trajectory in early life, and cardiovascular and metabolic risks in early adulthood: EPICure study. Arch Dis Child Fetal Neonatal Ed 2021;106:149-55. doi: 10.1136/archdischild-2020-319328 pmid: 32796060

64 Reddy UM, Rice MM, Grobman WA, etal. Serious maternal complications after early preterm delivery (24-33 weeks' gestation). Am I Obstet Gynecol 2015;213:538. doi: 10.1016/j.ajog.2015.06.064 pmid: 26164696

65 Pittara T, Vyrides A, Lamnisos D, Giannakou K. Pre-eclampsia and long-term health outcomes for mother and infant: an umbrella review. BJOG 2021;128:1421-30. doi: 10.1111/1471-0528.16683 pmid: 33638891

66 Sneider K, Christiansen OB, Sundtoft IB, Langhoff-Roos J. Recurrence of second trimester miscarriage and extreme preterm delivery at 16-27 weeks of gestation with a focus on cervical insufficiency and prophylactic cerclage. Acta Obstet Gynecol Scand 2016;95:1383-90. doi: 10.1111/aogs.13027 pmid: 27663202

67 Lykke JA, Paidas MJ, Langhoff-Roos J. Recurring complications in second pregnancy. Obstet Gynecol 2009;113:1217-24. doi: 10.1097/AOG.0b013e3181a66f2d pmid: 19461415

68 Koliouli F, Gaudron CZ, Raynaud J-P. Stress, coping, and post-traumatic stress disorder of French fathers of premature infants. Newborn Infant Nurs Rev 2016;16:110-4doi: 10.1053/j.nainr.2016.08.003

69 Barthel D, Göbel A, Barkmann C, Helle N, Bindt C. Does birth-related trauma last? Prevalence and risk factors for posttraumatic stress in mothers and fathers of VLBW preterm and term born children 5 years after birth. Front Psychiatry 2020;11:575429. doi: 10.3389/fpsyt.2020.575429 pmid: 33384624

70 Nusinovici S, Olliac B, Flamant C, etal. Impact of preterm birth on parental separation: a French population-based longitudinal study. BMJ Open 2017;7:e017845. doi: 10.1136/bmjopen-2017-017845 pmid: 29150469

71 Thomson K, Moffat M, Arisa O, etal. Socioeconomic inequalities and adverse pregnancy outcomes in the UK and Republic of Ireland: a systematic review and meta-analysis. BMJ Open 2021;11:e042753. doi: 10.1136/bmjopen-2020-042753 pmid: 33722867

72 Wang Q, Benmarhnia T, Zhang $\mathrm{H}$, etal. Identifying windows of susceptibility for maternal exposure to ambient air pollution and preterm birth. Environ Int 2018;121:317-24. doi: 10.1016/j.envint.2018.09.021 pmid: 30241019

73 Faber T, Kumar A, Mackenbach JP, etal. Effect of tobacco control policies on perinatal and child health: A systematic review and meta-analysis. Lancet Public Health 2017;2:e420-37.

74 Bickerstaff M, Beckmann M, Gibbons K, etal. Recent cessation of smoking and its effect on pregnancy outcomes. Aust N ZJ Obstet Gynaecol 2012;52:54-8.

75 Patnode CD, Henderson JT, Coppola EL, etal. Interventions for tobacco cessation in adults, including pregnant persons: Updated evidence report and systematic review for the US Preventive Services Task Force. JAMA 2021;325:280-98

76 Stephenson J, Heslehurst N, Hall J, etal. Before the beginning: nutrition and lifestyle in the preconception period and its importance for future health. Lancet 2018;391:1830-41.

77 National Institute for Health and Care Excellence. Recommendations. NICE guideline NG201: Antenatal care. 2021. https://www.nice.org.uk/guidance/ng201/chapter/Recommendations.

78 Gao R, Liu B, Yang W, etal. Association of maternal sexually transmitted infections with risk of preterm birth in the United States. JAMA Netw Open 2021;4:e2133413.

79 Wingert A, Pillay J, Sebastianski M, etal. Asymptomatic bacteriuria in pregnancy: systematic reviews of screening and treatment effectiveness and patient preferences. BMJ Open 2019;9:e021347.

80 Hoffman MK, Goudar SS, Kodkany BS, etal. Low-dose aspirin for the prevention of preterm delivery in nulliparous women with a singleton pregnancy (ASPIRIN): A randomised, double-blind, placebo-controlled trial. Lancet 2020;395:285-93.

81 Story L, Simpson NAB, David AL, etal. Reducing the impact of preterm birth: preterm birth commissioning in the United Kingdom. Eur J Obstet Gynecol Reprod Biol 2019;3:100018.

82 EPPPIC Group. Evaluating Progestogens for Preventing Preterm birth International Collaborative (EPPPIC): Meta-analysis of individual participant data from randomised controlled trials. Lancet 2021;397:1183-94

83 He Y, Xie X, Tang W, etal. Maternal and paternal obesity and adverse pregnancy outcomes in China: a cohort study. Lancet 2017;390:S52.

This is an Open Access article distributed in accordance with the Creative Commons Attribution Non Commercial (CC BY-NC 4.0) license, which permits others to distribute, remix, adapt, build upon this work non-commercially, and license their derivative works on different terms, provided the original work is properly cited and the use is non-commercial. See: http://creativecommons.org/licenses/bync/4.0/. 